${ }^{1}$ Elman Boy*, ${ }^{2}$ Nanda Sari Nuralita ${ }^{1}$ Bagian IImu Kesehatan Masyarakat Fakultas Kedokteran U M SU

2Bagian IImu Kesehatan Jiwa Fakultas Kedokteran U MSU

Fakultas Kedokteran U niversitas M uhammadiyah Sumatera U tara, Jalan G edung Arca N 0.53 , Teladan Bar., Medan Kota, M edan, Sumatera U tara 20817,

Email: elmanboy@umsu.ac.id

\section{Peningkatan Kualitas Hidup Lansia Dengan Husnul Khatimah Care (Hukho Care)}

The Life Q uality Improvement Of Elderly People Through $\mathrm{H}$ usnul K hatimah Care (H ukho C are)

https:/ / doi.org/ 10.18196/ bdr.7269

\begin{abstract}
The elderly people's lifetime requires attentions, especially those related to the health in order that healthy and joyful lifestyle could be achieved. Healthy and joyful life quality for elderly people is expected to bring improvement towards life expectancy. Therefore, effort in improving the life quality of elderly people needs to be taken into account. The implementation of community service program, particularly the one addressed to the elderly people aims to: 1) perform the selection of cognitive function and elderly people's mood situation; and 2) follow up the selection results. The implementation method was conducted step-by-step, which was through the selection of cognitive function and elderly people's mood situation using Abbreviated Mental Test (AMT), whereas Workshop Husnul Khatimah Care (Hukho Care) was implemented for the selection results follow-up. AMT was used to measure the psychological condition and memory disorders; it was implemented through interview given to each of the elderly people. The Workshop Hukho Care was conducted through education as well as small and big group discussion. The result shows that $9 \%$ of the elderly people suffer from depression, $19 \%$ unstable, and $27 \%$ suffer from moderate memory disorder. Those who suffer from depression, psychologically unstable, and moderate memory disorders are entirely female. Female elderly people who are depressed, psychologically unstable and having moderate memory disorder shall require supports and attention from family, Puskesmas (Pusat Kesehatan Masyarakat/ Public Health Center), and local health department.

Keywords: Elderly people, AMT, Hukho care
\end{abstract}

\title{
PENDAHULUAN
}

Lingkungan V Kelurahan Pangkalan Mashur Kecamatan M edan Johor merupakan salah satu wilayah binaan Fakultas Kedokteran U niversitas M uhammadiyah Sumatera U tara (FK U M SU ), Fakultas Kedokteran U niversitas M uhammadiyah Sumatera U tara berkeinginan meningkatkan kualitas hidup lansia di wilayah binaannya tersebut. M asyarakat Lingkungan V Kelurahan Pangkalan M ashur Kecamatan M edan Johor yang telah berusia di atas 60 tahun terusmeningkat dari tahun ketahun. Peningkatan kuantitas lansia tersebut belum diikuti dengan kualitas kesehatan lansia yang bersangkutan. M eskipun Puskesmas - Pangkalan M ashur Kecamatan M edan Johor sudah membentuk Posyandu lansia, namun hanya sedikit Lansia yang datang berkunjung setiap bulannya. 


\section{5}

Menurunnya kemampuan lansia dalam melakukan aktivitas penting dalam kehidupannya sehari-hari secara mandiri misalnya ke kamar mandi dan berpakaian dan berjalan dari satu tempat ketempat lainnya yang men yebabkan mereka menjadi tergantung dengan orang lain (A rai et al. 2012; C arlson, M erel, and Yukawa 2015; Sharifah Rosida Syed A li 2012). Keterbatasaan yang dimiliki lansia ini menyebabkan banyak antara mereka yang mengalami depresi dan gangguan mental lainnya (Berghöfer et al. 2014). Tujuan pengabdian: 1) melakukan seleksi fungsi kognitif dan kondisi suasana hati lansia, 2) menindaklanjuti hasil seleksi.

\section{METODE PELAKSANAAN}

Khalayak sasaran adalah seluruh populasi lansia yang berusia 60 tahun atau lebih yang berdomisili di Lingkungan V Kelurahan Pangkalan M ashyur Kecamatan M edan Johor Kota M edan. Khalayak sasaran yag dipilih masuk dalam program ini adalah yang mampu hadir secara man diri ke lokasi acara. Khalayak sasaran atau responden diundang oleh tim pelaksanakan program pengabdian masyarakat melalui surat undangan dari Fakultas Kedokteran U M SU (Terlampir). Surat undangan ini diserahkan kepada Kepala Lingkungan V Kelurahan Pangkalan M ashur untuk diperbanyak dan dibagikan kepada khalayak sasaran yang dimaksud. Bahan dan alat-alat spesifik yang digunakan antara lain kuesioner seleksi abbreviated mental test (AMT). seleksi AMT dilakukan dengan menggunakan instrumen kuesioner yang dikeluarkan Kementrian Kesehatan Republik Indonesia tahun 2017. AM T terdiri dari 10 pertanyaan yang dapat mengukur kondisi kejiwaan dan gangguan ingatan lansia (Boy et al. 2019). Interpretasi kondisi kejiwaan lansia dapat berupa kondisi jiwa yang baik, labil, depresi, gelisah ataupun dalam kondisi cemas. Satu -persatu lansia di wawancara langsung dan hasilnya dituangkan dalam kuesioner. D aftar kehadiran sasaran dan daftar penerima uang tran sport serta souvenir berupa sembako (terlampir). Workshop H usnul K hotimah $\mathrm{C}$ are (H ukho $\mathrm{C}$ are) dilakukan untuk menindaklanjuti hasil seleksi Workshop $\mathrm{H}$ ukho $\mathrm{C}$ are dilakukan melalui edukasi agar lansia mengisi sisa usia dengan kegiatan yang diperintahkan oleh ajaran agama seperti berpikir positif, melaksanakan amal sholih, dan menjadi tauladan di dalam keluarga (A rai et al. 2012, Velasco-G onzalez and Rioux 2014). LCD proyektor dilengkapi dengan layar proyektor, pointer dan laptop digunakan untuk mempresentasikan perawatan kesehatan lansia husnul khotimah care. Adapun alur kegiatan program pengabdian masyarakat ini dilakukan sebagaimana tercantum di samping. 


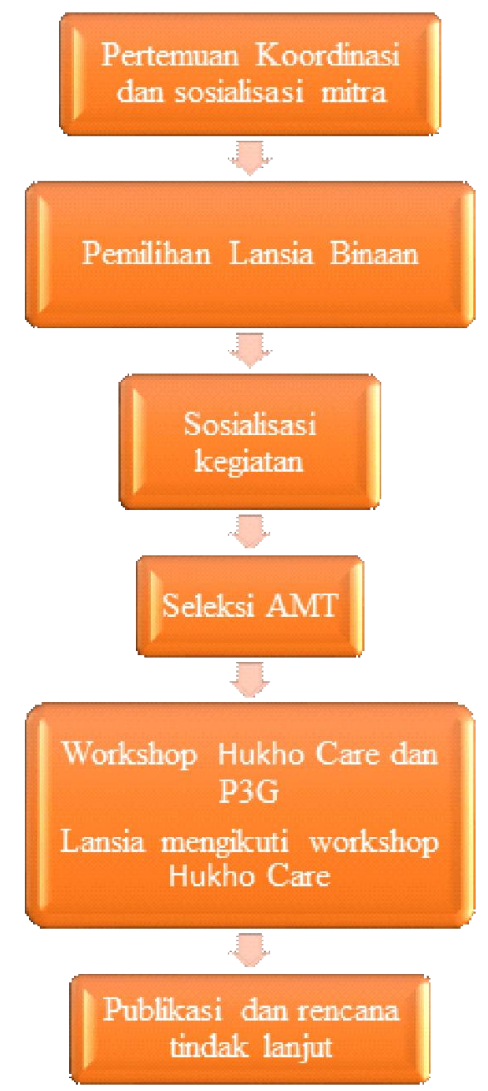

Pada tahapan pengumpulan dan analisis data, pengumpulan data dilakukan melalui wawancara terhadap responden satu persatu sesuai dengan formulir AMT yang telah tersedia. W awancara langsung dilakukan oleh tim pelaksana program. H asil wawancara dituangkan ke dalam formulir AMT. setiap responden diminta untuk menjawab pertanyaan tersebut. Pengumpul data akan memberi tanda silang $(X)$ pada nilai 0 (nol) jika salah dan 1 (satu) jikajawaban yang diberikan responden benar. U ntuk 10 pertanyaan 1 sampai dengan 10, skor yang telah diberikan kemudian dijumlahkan. Nilai skor maksimum adalah 10 dan nilai minimum adalah 0. Interpretasi, skor 8-10 men unjukkan fungsi daya ingat lansia normal. Skor 4-7 menunjukkan lansia mengalami gangguan ingatan sedang. Skor 0-3 menunjukkan lansia mengalami gangguan ingatan berat. Suasana perasaan hati responden diamati ketika wawancara berlangsung dan peneliti memberikan pilihan dengan memberi silang $(X)$ pada suasana hati lansia yang sesuai 1. Baik, 2. Labil, 3. D epresi, 4. Gelisah, 5. C emas (Boy et al. 2019; C arlson, M erel, and Yukawa 2015).

\section{HASIL DAN PEMBAHASAN}

Jumlah peserta yang diundang adalah 13 orang, hadir sebanyak 12 orang dan tidak 
hadir sebanyak 1 orang. Peserta kegiatan ini diikuti oleh 12 orang responden dengan 83\% adalah perempuan dan sisanya adalah laki-laki. Hasil seleksi AMT didapati 9\% lansia mengalami depresi, 19 persen dalam kondisi labil dan selebihnya dalam kondisi normal, didapati pula lansia men galami gan gguan ingatan sedang sebesar $27 \%$ dan sebesar $73 \%$ lansia lainnya adalah normal. Tidak ditemukan lansia dengan gangguan ingatan berat. Seluruh responden dengan keadaan depresi, kondisi jiwa labil serta lansia dengan gangguan ingatan sedang adalah perempuan. Para peserta mengikuti workshop dengan antusias, setelah pemaparan tim beberapa pertanyaan dan tanggapan di-sampaikan oleh peserta, antara lain pertanyaan dan tanggapan dari peserta mengenai bagaimana menyadarkan anak yang berada jauh agar lebih sering melakukan komunikasi dengan orang tua. Sesi workshop ini ditutup dengan penyerahan bantuan sembako oleh tim kepada peserta disaksikan oleh Kepala Lingkungan V Kelurahan Pangkalan Mashur Kecamatan M edan Johor dan foto bersama. Hasil pemeriksaan tampak dalam grafik dibawah ini :

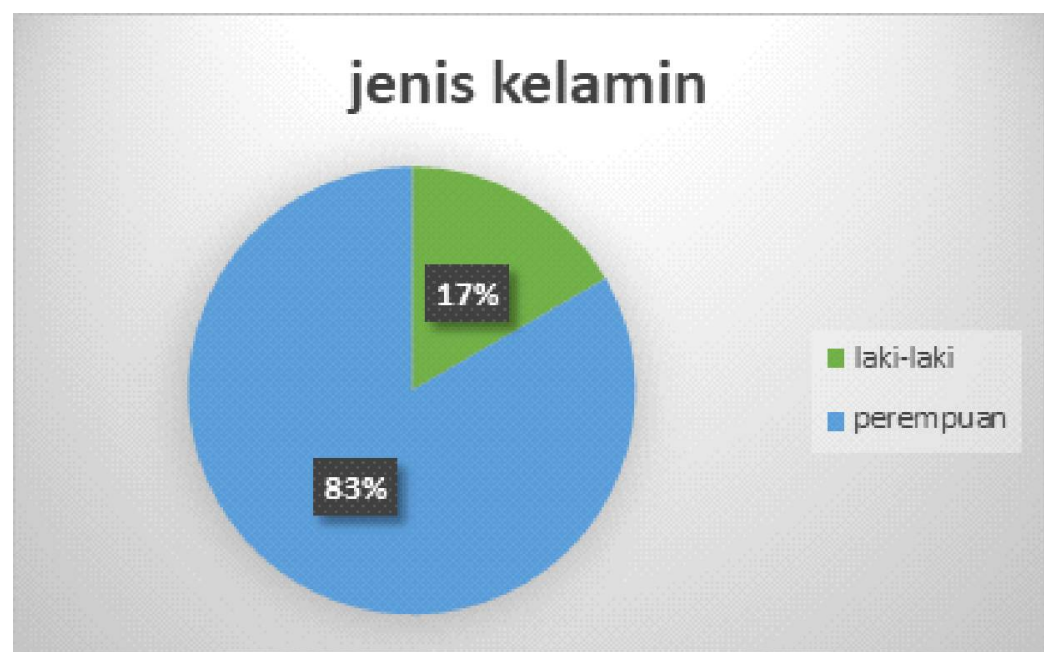

Diagram 1. Distribusi Persentase Responden Berdasarkan J enis Kelamin

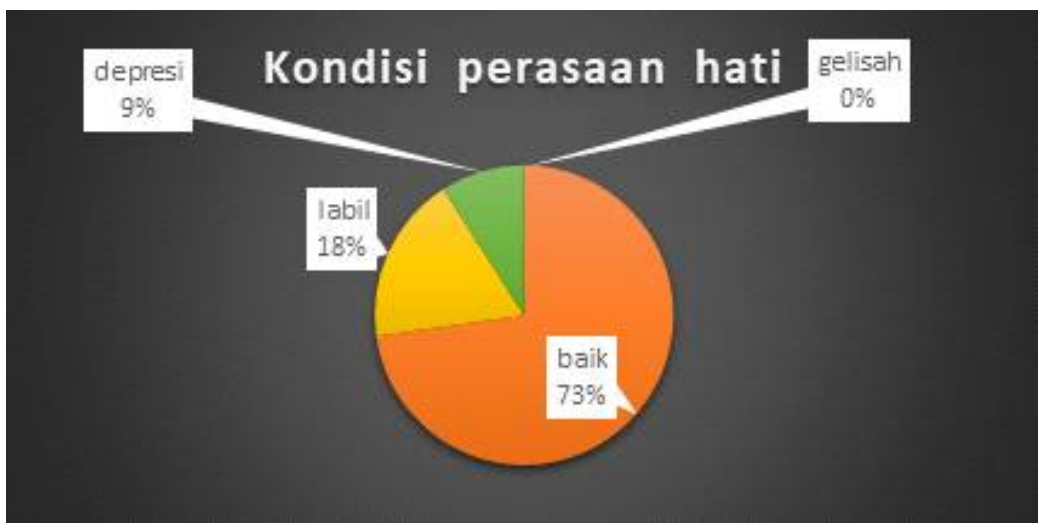

Diagram 2. Distribusi Persentase Responden Berdasarkan Kondisi Perasaan Hati 


\section{GANGGUAN INGATAN PADA LANSIA}

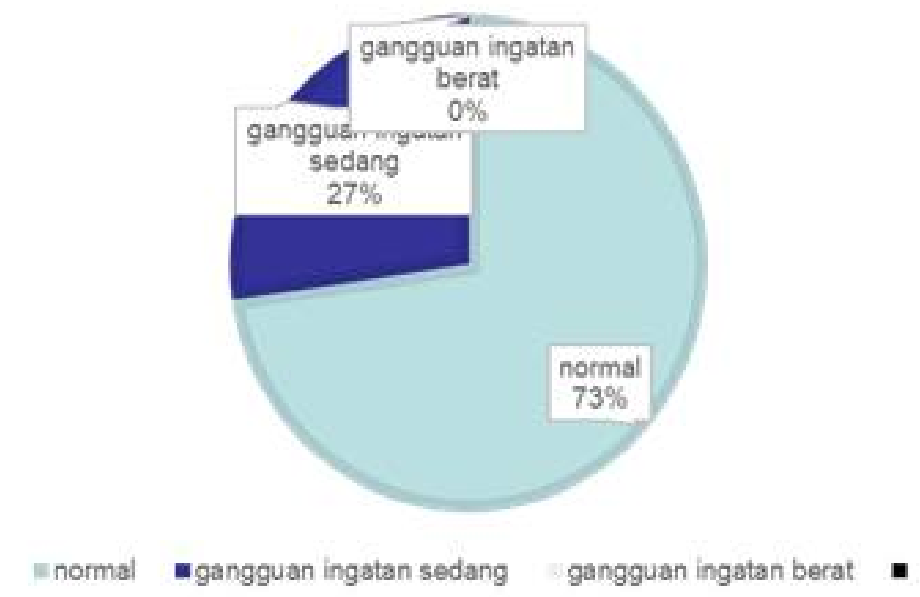

Diagran 3. Distribusi Persentase Responden Berdasarkan Gangguan Ingatan

Pembahasan : lansia berusia dalam rentang 60-74 tahun merupakan kelompak lansia yang paling besar dijumpai. Pada kelompok usia ini sebagian besar masih dapat melakukan aktivitas sehari-hari secara mandiri, sehingga mereka masih dapat menerima undangan dan menghadirinya (Shermon, Vernon, and M CG rath 2015). Pada kelompok lansia ini mereka juga dapat melakukan komunikasi dengan baik, mendengar dengan baik, dan memberikan pendapat mereka dengan sangat baik, sehingga kemungkinan biasa yang terjadi karena kesalahpahaman sangat sedikit kemungkinan terjadi (H endry et al. 2016). Secara umum umur harapan hidup lansia perempuan lebih baik dari laki-laki, hal ini menyebabkan responden lebih banyak dari kalangan kaum perempuan. $\mathrm{H}$ al ini sesuai dengan penelitian yangtelah kami lakukan sebelumnya (Boy et al. 2019). Pada penelitian kami sebelumnya yakni hasil seleksi AMT pada lansia yang datang ke puskesmas ditemukan sebanyak 26,7\% lansia men galami gangguan ingatan tingkat sedang, hal ini tidak berbeda jauh dengan hasil program yang kami lakukan ini- (Boy et al. 2019).

$G$ angguan ingatan dapat meningkat dengan semakin bertambahnyausia lansia ( $\mathrm{H}$ endry et al. 2016). Namun hal ini dapat diperlambat dengan berbagai aktivitas yang dilakukan oleh lansia itu sendiri, seperti aktivitas ibadah, sosial ekonomi, dan disertai dengan dukungan yang positif dari lingkungan sekitar (June, 2016). A ktivitas ibadah dan keyakinan yang pen uh kepada sang pencipta mendorong lansia lebih tenang dan nyaman dalam menjalani kehidupannya sehari-hari. $\mathrm{H}$ al ini disebabkan keyakinan bahwa tidak akan terjadi sesuatu kepada manusia kecuali atas izin Allah SW T, sang pencipta manusia. Aktivitas ibadah yang didasari keimanan dan ilmu pengetahuan memberi keyakinan kepada lansia bahwa semua manusia pada suatu ketika mengakhiri hidupnya di dunia 
ini dan hal ini merupakan suatu kepastian yang akan terjadi. M eskipun demikian keimanan lansia akan men dorong ia untuk tetap beruasaha mempertahankan kesehatan jasmani dan rohani serta kehidupan sosial karena Tuhan telah menjanjikan bahwa nasib sesorang tidak akan berubah bila manusia tidak berupaya mengubah kehidupannya sendiri. $\mathrm{H}$ al-hal seperti ini men dorong lansia untuk termotivasi menjalani kehidupannya dengan sungguh-sungguh dan mempersiapkan akhir hidupnya dengan sungguh-sungguh pula ( $\mathrm{N}$ g et al. 2011,; Velasco-G onzalez and Rioux 2014). Transfer ilmu pengetahuan kepada lansia sebagai kader bagi diri sendiri, keluarga dan lingkungan dapat bermanfaat meningkatkan pengetahuan dan motivasi mereka (2015).

\section{SIM PULAN}

Pembinaan lansia di desa-desa sangat diperlukan untuk mempertahankan dan meningkatkan kesehatan lansia baik jasmani maupun rohani serta produktivitas seharihari. M asih ditemukan lansia dalam keadaan depresi dan dengan kondisi jiwa yang labil serta mengalami gangguan ingatan yang umumnya terjadi pada lansia perempuan yang memerlukan dukungan dan perhatian dari berbagai pihak terkait terutama dukungan keluarga dan lingkungan sekitarnya. M en dekatkan lansia kepada aktivitas keagamaan akan mendorong lansia lebih siap menghadapi akhir kehidupannya.

\section{UCAPAN TERIMA KASIH}

U capan terima kasih terutama kepada U niversitas M uhammadiyah Sumatera U tara sebagai pemberi dana melalui kontrak program Pen gabdian kepada M asyarakat nomor. 195/ II.3-AU / U M SU -LP2M / C / 2019. U capan terima kasih juga kami diberikan kepada Kepala Lingkungan V Kelurahan Pangkalan Mashur Kecamatan Medan Johor dan Pengurus badan Kemakmuran M asjid Nurul Huda, seluruh lansia yang mengikuti program ini atas perannya memberikan sumbangan moral dan material yang sangat berarti bagi program pen gabdian masyarakat ini.

\section{DAFTAR PUSTAKA}

Arai, Hidenori et al. 2012. "Toward the Realization of a Better Aged Society: Messages from Gerontology and Geriatrics." Geriatrics and Gerontology International.

Berghöfer, Anne et al. 2014. "Screening for Depression and High Utilization of Health Care Resources Among Patients in Primary Care." Community Mental Health Journal.
Boy, Elman et al. 2019. "Utilization of Comprehensive Geriatric Assessment (P3G) in Primary Health Center at Medan City and Deli Serdang District of North Sumatera Province Indonesia 2018." International Journal of Human and Health Sciences (IJHHS).

Carlson, Charlotte, Susan E. Merel, and Michi Yukawa. 2015. "Geriatric Syndromes and Geriatric 
Assessment for the Generalist." Medical Clinics of North America.

Hendry, Kirsty et al. 2016. "Evaluation of Delirium Screening Tools in Geriatric Medical Inpatients: A Diagnostic Test Accuracy Study." Age and ageing. June, Girvin. 2016. "The Quality of Care." Elderly Care.

$\mathrm{Ng}$, Tze Pin, Ma Shwe Zin Nyunt, Peak Chiang Chiam, and Ee Heok Kua. 2011. "Religion, Health Beliefs and the Use of Mental Health Services by the Elderly." Aging and Mental Health.

Sharifah Rosida Syed Ali. 2012. "Pengaruh Faktor Peribadi, Sokongan Sosial, Tahap Kesihatan Dan Agama Ke Atas Warga Tua Produktif." J ournal Art and Sciences.

Shermon, Elizabeth, Lucy O. Vernon, and Adrian J. McGrath. 2015. "Cognitive Assessment of Elderly Inpatients: A Clinical Audit." Dementia and Geriatric Cognitive Disorders Extra.

Velasco-Gonzalez, Lucy, and Liliane Rioux. 2014. "The Spiritual Well-Being of Elderly People: A Study of a French Sample." J ournal of Religion and Health.

Boy, Elman, et all. 2015. “Efektifitas Pelatihan Kader Kesehatan Dalam Penanganan Tuberkulosis Di Wilayah Binaan." Jurnal Pendidikan Kedokteran Indonesia; The Indonesian J ournal of Medical Education. 